\title{
Undergraduates' Political Participation Behaviors in Public Universities of Hebei Province, China
}

\author{
Yanan Yang ${ }^{1,2}$, Nan Xia ${ }^{1,3}$, Zaid Bin Ahmad ${ }^{1}$, Jayum Anak Jawan ${ }^{1}$, Ahmad Tarmizi Talib ${ }^{1}$ \\ ${ }^{1}$ Department of Government and Civilization Studies, Faculty of Human Ecology, Universiti Putra Malaysia, \\ Serdang, Malaysia \\ ${ }^{2}$ Scocial Science Department, Chengde Medical University, Chengde, China \\ ${ }^{3}$ School of International Education, Chengde Medical University, Chengde, China \\ Corresponding author: Zaid Bin Ahmad, Department of Government and Civilization Studies, Faculty of Human \\ Ecology, Universiti Putra Malaysia, Serdang, Selangor, Malaysia. Tel: 603-8946-7068. E-mail: \\ zaid_a@upm.edu.my
}

Received: June 7, 2018 Accepted: June 19, $2018 \quad$ Online Published: July 27, 2018

doi:10.5539/ass.v14n8p132 URL: https://doi.org/10.5539/ass.v14n8p132

\begin{abstract}
Political participation is a necessity of human life and the level of it reflects the degree of democracy which can be considered not only the right but also the obligation. Hebei province as a populous province has a large population of undergraduates, especially the expansion the university education policy carrying out in 2008. For the undergraduates in Hebei Province, they do not have adequate political knowledge, political skills and rarely practice in political activities. The objective of this article is to propose and evaluate students' political participation behaviors in Hebei public universities of China. Data of this article is based on two sources; primary data were collected through questionnaire and 1990 informants were selected based on the cluster sampling method, the main statistical method for evaluation of research hypotheses is on the basis of on the basis of SmartPLS and SPSS software, meanwhile, secondary data which were collected from journal articles, reports and so on. Findings of this study indicate that, the level of students' political participation was low in public universities in Hebei province in China. Moreover, the author elaborated four reasons that led to the low political participation behaviors in public universities of Hebei Province, which were the weak economic foundation, the backwardness of the cultural environment, the unsound political system and the influence of traditional culture. In addition, the author suggested that political participation among Hebei province public universities students need to improve and develop.
\end{abstract}

Keywords: undergraduates, political participation, public universities, Hebei Province

\section{Introduction}

Political participation is a necessity of human life and the level of it reflects the degree of democracy which can be considered not only the right but also the obligation. Hebei province as a populous province has a large population of undergraduates, especially the expansion the university education policy carrying out in 2008 . Along with the Jing-Jin-Ji integrated policies which carried out on 2013 and have become a significant strategy of the whole China, Hebei province plays a significant role to implement this policy and develop itself not only in politics and economy, but also in culture and education following the new opportunity. The undergraduate is a unique group who is able to be the elites, governor, and politician and must be the person who takes part in the social lives. For the undergraduates in Hebei Province, they do not have adequate political knowledge, political skills and rarely practice in political activities; however, the undergraduate is a necessary group to participate the social and governmental activities.

In China, the history of students' political participation can draw back to the Revolution of 1919; however, the youth disengage in the political activities appear obviously in the modern society. Youth political participation exist some problems as follows: their social subject consciousness is weakness and begun to appear political apathy in the process of political participation (Zhao \& Tang, 2008), their participatory motivation presents utilitarian and purposefulness gradually (Gao, 2009), they have ambiguous cognition on political participation and lack of political theoretical knowledge, their behavior and consciousness of political participation are 
difference, and online participation is more than traditional participation (Jiang \& Liu, 2013), in order to explore the experience and the level in the process of political participation of undergraduates and the researcher concentrates the energy to do the investigation in undergraduates' political participation. Thus, the objective of this article is to propose and evaluate students' political participation behaviors in Hebei public universities of China.

\section{Methodology}

Data of this article is based on two sources; the primary data were collected through questionnaire. This research adopted cluster sampling method to select samples, because it is very difficult to list all the undergraduates from scattered target population and choose the sample from them. Therefore, 5 different universities and colleges in Hebei province were chosen. The questionnaire was explained and confidentiality was promised. And how to fill out questionnaire was instructed. In the current research, the main statistical method for evaluation of research hypotheses is on the basis of SmartPLS and SPSS software, the G*Power software was used to calculate the sample size required for this research. Therefore, the sample size of the study was determined to be 1990 informants based on the cluster sampling method. Meanwhile, secondary data were collected from journal articles, reports and so on.

\section{Undergraduates' Political Participation Behaviors in Public Universities of Hebei Province}

Measuring the students' participation level is aim to achieve the objective using eight participatory activities including Political Participation Behavior (PPB) 1 to PPB8 as table 1 shown in the following. Investigations of political participation using survey techniques which confined four types including vote, campaign activities, protest and political contact based on the concept with eight behaviors. The descriptive analysis of variables from 5-point Likert scale is presented in $1=$ never, $2=$ rarely, $3=$ sometimes, $4=$ often and $5=$ always. After that, put the five groups into three levels: low, moderate and high in order to test the relation between political participation and the benefit of it.

Table 1. Descriptive Result of Each Political Activity

\begin{tabular}{|c|c|c|c|c|c|c|c|c|c|c|c|}
\hline \multirow{2}{*}{ Modes } & \multirow{2}{*}{ Item } & \multirow{2}{*}{ Behaviors } & \multirow{2}{*}{ Mean } & \multirow{2}{*}{ SD } & \multirow{2}{*}{ Min. } & \multirow{2}{*}{ Max. } & \multicolumn{5}{|c|}{ Percentage } \\
\hline & & & & & & & Never & Rarely & Sometimes & Often & Always \\
\hline \multirow{12}{*}{$\begin{array}{l}\text { Campaign } \\
\text { Activities }\end{array}$} & \multirow{3}{*}{ PPB1 } & \multirow{3}{*}{ Attend a political meeting or rally } & \multirow{3}{*}{2.11} & \multirow{3}{*}{.988} & \multirow{3}{*}{1} & \multirow{3}{*}{5} & 639 & 700 & 488 & 126 & 37 \\
\hline & & & & & & & $32.1 \%$ & $35.2 \%$ & $24.5 \%$ & $6.3 \%$ & $1.9 \%$ \\
\hline & & & & & & & \multicolumn{2}{|c|}{ Low: $67.3 \%$} & Middle: $24.5 \%$ & \multicolumn{2}{|c|}{ High: $8.2 \%$} \\
\hline & \multirow{3}{*}{ PPB2 } & \multirow{3}{*}{$\begin{array}{l}\text { Spend money supporting a deputy } \\
\text { or party }\end{array}$} & \multirow{3}{*}{2.39} & \multirow{3}{*}{.990} & \multirow{3}{*}{1} & \multirow{3}{*}{5} & 420 & 652 & 670 & 213 & 35 \\
\hline & & & & & & & $21.1 \%$ & $32.8 \%$ & $33.7 \%$ & $10.7 \%$ & $1.8 \%$ \\
\hline & & & & & & & \multicolumn{2}{|c|}{ Low: $53.9 \%$} & Middle: $33.7 \%$ & \multicolumn{2}{|c|}{ High: $12.5 \%$} \\
\hline & \multirow{3}{*}{ PPB3 } & \multirow{3}{*}{$\begin{array}{l}\text { Persuade people to vote for a } \\
\text { particular deputy or } \\
\text { representative }\end{array}$} & \multirow{3}{*}{2.34} & \multirow{3}{*}{1.033} & \multirow{3}{*}{1} & & 496 & 613 & 624 & 215 & 42 \\
\hline & & & & & & 5 & $24.9 \%$ & $30.8 \%$ & $31.4 \%$ & $10.8 \%$ & $2.1 \%$ \\
\hline & & & & & & & Low: 55 & & Middle: $31.4 \%$ & High: 1 & $2.9 \%$ \\
\hline & & & & & & & 545 & 574 & 592 & 217 & 62 \\
\hline & PpB4 & Camied a poster or placed a & 2.34 & 1.085 & 1 & 5 & $27.4 \%$ & $28.8 \%$ & $29.7 \%$ & $10.9 \%$ & $3.1 \%$ \\
\hline & & & & & & & Low: 56 & & Middle: $29.7 \%$ & High: 1 & $4.1 \%$ \\
\hline & & & & & & & 248 & 514 & 824 & 319 & 85 \\
\hline Vote & PPB5 & Vote & 2.74 & 1.010 & 1 & 5 & $12.5 \%$ & $25.8 \%$ & $41.4 \%$ & $16 \%$ & $4.3 \%$ \\
\hline & & & & & & & Low: 38 & & Middle: $41.4 \%$ & High: 2 & $0.3 \%$ \\
\hline & & & & & & & 1225 & 310 & 296 & 117 & 42 \\
\hline Protest & PPB6 & Participate in a peaceful & 1.71 & 1.053 & 1 & 5 & $61.6 \%$ & $15.6 \%$ & $14.9 \%$ & $5.9 \%$ & $2.1 \%$ \\
\hline & & & & & & & Low: 77 & & Middle: $14.9 \%$ & High: 7 & $9 \%$ \\
\hline & & & & & & & 841 & 539 & 414 & 145 & 51 \\
\hline & PPB7 & Contact and understand a civil & 2.01 & 1.074 & 1 & 5 & $42.3 \%$ & $27.1 \%$ & $20.8 \%$ & $7.3 \%$ & $2.5 \%$ \\
\hline Political & & & & & & & Low: 69 & & Middle: $20.8 \%$ & High: 9 & $9 \%$ \\
\hline Contact & & & & & & & 1068 & 394 & 349 & 135 & 43 \\
\hline & PPB8 & Contact an elected municipal & 1.84 & 1.075 & 1 & 5 & $53.7 \%$ & $19.8 \%$ & $17.5 \%$ & $6.8 \%$ & $2.2 \%$ \\
\hline & & & & & & & Low: 73 & & Middle: $17.5 \%$ & High: 9 & \\
\hline
\end{tabular}

\subsection{Descriptive In General}

It can be seen from table 1 that voting is direct political activity which impact of citizen on governmental performance. Vote with mean score $2.74(1-5 \mathrm{scale})$ is the highest among the eight behaviors which stands in the middle degree. Demonstration (PPB6) belonging to protest behavior is the lowest among the eight behaviors with the mean statics 1.71 in general, and $1225(61.6 \%)$ students never played. PPB1, 2, 3 and 4 are attributed to campaign activities (CA) group, and the level tested by mean score displays lower than vote but higher than protest behavior. At last, the political contact behavior contains PPB7 and PPB8, the mean level between the two activities presents long distance, the former one is 2.01 and the latter is 1.84. Except election is in middle level, other behaviors are in low level which are resulted from the statistics hint. 
Campaign activities (CA) constitutes standard political participation which can exert pressure or communicate information with other citizens in the process of participation (Verba \& Nie, 1972). Table 1 displays that slightly from $32.1 \%$ to $21.1 \%$ of the total respondents never participate into $\mathrm{CA}$ domain tested by the four behaviors .Compared to protest and PC behaviors, the level of CA improves a little bit, but it is not obvious. Absent in attending meeting or speech is the highest with $32.1 \%$ in CA domain, which because it needs the expense. It is possible for students to have time conflicts between participation and coursework, academic subjects stand in privilege position, participatory activities have to shun the way except the students are obsessed with politics. Outcome-oriented tends to be the second reason why the respondents refused to CA, the more work for voting respondents do, the less feedback can be obtained. The core value can be attributed to the third reason, done works in this domain, improving how many citizens to participate cannot be calculated and adding how much competitive ability cannot be measured. Therefore, respondents reject CA behavior because of the effects of the behavior itself.

Vote (PPB5) is not only the right but also the obligation of the citizen which required by the Constitution of PRC. In China' political reality, citizen can directly vote the gross representatives. Vote as the standard political participatory behavior and some of the scholars stated "vote is the unique activity which provides equal chance for each citizen to participate into politics" (Zhou, 2014), and the result demonstrates the assumption and citizen more positively participate than other behaviors. Vote as the only political act presented in table 1 that can influence the governmental behavior directly, $87.5 \%$ students are participate into rarely, sometimes, often and always degree that indicates majority of respondents in this research are positive enough to vote in universities. Vote is the citizen's power and obligation, the obvious increasing tendency comparing with the other behaviors indicates the right and participatory ideology has improved.

As for the protest behavior, the Constitution of PRC stipulates explicitly any citizen has the right to protest; however, the rules are in fuzzy states, not all the protest behavior can be admitted by the government. And in detail, about $61.6 \%$ students refused to participate in demonstration that indicates a majority of students did not through protest behavior in order to achieve political participation. If cannot compare the benefit and cost, not to do is better than do, pursuing the maximum benefit becomes an important reason. Undergraduates as the high knowledgeable group, in case participate into demonstration, which was deemed to law breaking or social riot, that would record into file and influence the future of students; whereas not to do, just inactive into participation even not exercise the participatory power which cannot be judged as right or wrong. The undergraduate in university accept, master and practice the knowledge totally in order to achieve professional future, once because the demonstration was reported into the "black file" which bad for finding job without right political orientation. The loss outweighs the gain, usually students choose the maximum benefits and shun bad influence, especially being vindicated by the government; therefore, rejecting demonstration seems better for future. Therefore, rational choice and benefit maximization are likely to be the reason why protest behavior stands in low level.

Individuals with particular concerns contact with government candidates or officials is displayed by political contact in this research, including two behaviors, one is contacting civil servant (governor) and the other one is contacting NPC deputy member. Closely to $55 \%$ students never contact an elected politician and $42.3 \%$ students refuse to contact a civil servant to explain or complain issues. PC domain provides the channel to express opinions, suggestions and recommendations in the process of political activism in order to influence government policy making; however, students' refusal behavior indicates PC is not an effective way to participate. In PRC electoral and grassroots' democracy system, citizen has the right to vote people's representatives in primarily (Lin, 2011), while contacting representatives is likely difficult to practice because of the internal and external reasons. First, it is difficult to contact strategy, considering the way which is suitable public or secret, individual or group institution, and direct face to face or electricity contact? The tough way restricts students to try to contact. Secondly, failure experience is enough to be the obstacle no matter from students' or others. Contacting failure provides the hurdle to express directly lead to no chance; communication and appeal failure supply the ineffective for influence the government. Thirdly, the undergraduate is both the student and the social human beings; focus study is the first task for each student in university. Participation in this process without adding the academic remarks, and even providing suggestions to the officials without achieving influence policy-making confidence that gradually dampen the students' enthusiasms, wherefore, never involvement in PC is because of channel limitation and result-orientated motivations. Hence, strategy, process and results lead students take part into politics negatively and stand in low level.

\subsection{The Level of Respondents for Political Participation}

Political participation in this research is aim to influence policy-making and participate in the process of politics, it is wider than some scholars requires political participation is only the activities in voting and narrower than 
some scholars claimed all the activities concerned politics.

Table 1 presents the proportion of students performing each of eight acts of political participation. Items originally containing four types of participation have been five-point for this presentation, and the division points can be inferred from the brief descriptions given in the table. It is quite clear from these frequency distributions that most acts of political participation are performed by most portions of undergraduates which displays by calculating a mean score for the eight items, the minimum scale 1 was subtracted from the maximum scale 5 and then divided by the number of group 3. Hence, the mean score range of 1 to 2 was classified as low participation, 3 as a moderate participation, and 4 and 5 as high participation.

Table 2. Level of Respondents' Political Participation ( $\mathrm{N}=1990)$

\begin{tabular}{|c|c|c|c|c|c|c|c|}
\hline \multicolumn{2}{|c|}{ Variable } & & & \multirow{3}{*}{$\begin{array}{l}\text { Mean } \\
9.4784\end{array}$} & \multirow{2}{*}{$\frac{\text { SD }}{6.39753}$} & \multirow{2}{*}{$\frac{\text { Min }}{8}$} & \multirow{2}{*}{$\begin{array}{c}\text { Max } \\
40\end{array}$} \\
\hline & & $N$ & $N \%$ & & & & \\
\hline Low & $8-20$ & 1381 & $69.39 \%$ & & & & \\
\hline Moderate & $21-28$ & 498 & $25.03 \%$ & & & & \\
\hline High & $29-40$ & 111 & $5.58 \%$ & & & & \\
\hline
\end{tabular}

Political participation is seen as a total behavior, including four types within eight single behaviors. A total participatory score for each respondent was computed by adding all scores from eight participatory behaviors. In order to measure the PP, transforming the eight behaviors into a whole, hence the scale range from 8 to 40 based on the each behavior. After calculating a mean score for PP, the range when was less than 20 as low level, more than 21 and less than 28 as moderate level, above 29 to 40 as high level.

The level of students' political participation was low in public university in Hebei province in China. Because the mean score for the political participation was Mean $=17.4784, \mathrm{SD}=6.39753$, which was slightly lower than 21 which indicate the middle level based on Table 2. According to the results, 111 respondents taking account into $5.58 \%$ has high level in participatory behaviors in politics as well as $25.03 \%$ students stood in moderate level; obviously, the majority 1381 students in the whole 1990 respondents were in low level. Closely to $70 \%$ respondents were in low level PP, hence, the respondents' level of political participation through participatory activities was considered low.

\subsection{Background and Political Participation}

In order to compare the scores of two different groups, t-test was used on gender and the formula for eta squared in t-test is as follows:

$$
\text { Eta squared }=\frac{t^{2}}{t^{2}+(N 1+N 2-2)}=\frac{t^{2}}{t^{2}+(728+1262-2)}=\frac{t^{2}}{t^{2}+1988}
$$

Meanwhile, in comparing the mean scores more than two groups (gender, hometown, major, interest, family income and knowledge-store), one-way analysis of variance (ANOVA) would be used to compare groups and for the effect size statistics and the Eta square of formula in the ANOVA is:

$$
\text { Eta square }=\frac{\text { Sum of squares between groups }}{\text { Total sum of squares }}
$$

The criteria for interpreting the value are: $0.01=$ small effect, $0.06=$ moderate effect and $0.14=$ large effect (Cohen, 1988) in both methods of t-test and ANOVA.

\subsubsection{Gender}

Any meaningful analysis of PP should be determined beginning from demographic profile. Although female and male students have significance on PP, the magnitude of difference with eta square was small or small to moderate.

\begin{tabular}{|c|c|c|c|c|c|c|c|c|c|c|c|}
\hline & \multirow{2}{*}{ Gender } & \multirow{2}{*}{$N$} & \multirow{2}{*}{$\begin{array}{l}\text { Mean for } \\
\text { Group }\end{array}$} & \multirow{2}{*}{$\begin{array}{l}\text { Std. } \\
\text { Deviation }\end{array}$} & \multirow{2}{*}{ Mean } & \multirow{2}{*}{\begin{tabular}{|l|} 
Mean \\
Difference
\end{tabular}} & \multicolumn{2}{|c|}{$95 \%$ Confidence Interval of the Difference } & \multirow{2}{*}{$t$ value } & \multirow{2}{*}{ p-value } & \multirow{2}{*}{ Eta square } \\
\hline & & & & & & & Lower & Upper & & & \\
\hline \multirow{3}{*}{ Pp } & & & & & 17.4784 & 2.82174 & 2.22397 & 3.41951 & 9.260 & $0.000^{* * *}$ & 0.041 \\
\hline & male & 728 & 19.2679 & 6.92808 & & & & & & & \\
\hline & female & 1262 & 8.4461 & 5.82836 & & & & & & & \\
\hline \multicolumn{12}{|c|}{ Note: ${ }^{*} p^{<} 0.05 ; * * p^{<} 0.01 ; * * * p^{<} 0.001$} \\
\hline
\end{tabular}

Table 3. The results of independent-samples t-test between Genders for Political Participation 
Based on the results of Table 3, the mean level of PP is 17.4784, which stands in the low level. Through independent samples t-test, it is easy to find male students are more positively participate into politics because males $(\mathrm{M}=19.2679, \mathrm{SD}=6.92808)$ and females $(\mathrm{M}=16.4461, \mathrm{SD}=5.82836)$ which was displayed at Table 5.3 . Male and female students have statistical significant difference on PP with $t(1990)=9.260, p=.000^{* * *}$, (two-tailed). And the magnitude of the difference in means (mean difference $=2.82174,95 \%$ CI: 2.22397 to 3.41951) in this research, although gender has effect on low level participation, in fact, the magnitude was small to moderate.

Compared with the mean level of the total 1990 respondents is 17.48 , it is obvious to obtain that male student are good at political participation, and the mean level is higher than female students' and closely to middle level; whereas female students' level further lower than the mean level, although the mean level has already stands in low level.

Although "The Constitution of the PRC" requires that the citizens who reached eighteen years have the equal right to participation no matter the gender. The reality is opposite, the effect size is 0.041 that presents the difference between female and male students' participation level influenced by gender is small to moderate. The result indicates the male are sensitive to politics, and explore political progress bravely; whereas the female are likely to collect most of information, after gain the results to take action, compared with the male students, female students are a little bit timid and intricate.

The student accept higher education at the same time, the obvious difference between male and female students indicates male students' ability in political participation level is higher than female's, they are more sensitive and energetic to participate, and the male students are good at obtaining information and improving the efficiency. Male students are more positively to participate into politics than female students based on Table 3; however, gender has small to moderate effect to influence students' political participation level, which has violated the requirements of Constitution of ROC for gender; hence, examine the other factors to influence participation is necessary.

\subsubsection{Hometown}

A one-way between-groups analysis of variance was conducted to explore the impact of hometown on PP. The participants are divided into three groups, including Group1 (CITY), Group2 (TOWN) and Group3 (COUNTRY). According to the results of Table 4, there was no significant difference among three groups of hometown on PP, because the $p>.05$. The effect of hometown for the students have no influence on PP that obeys the requirement of the Constitution of ROC and corresponded to the assumption of Benjamin, Pateman and Macpherson.

Table 4. The results of One-way ANOVA between Hometowns for political participation behaviors

\begin{tabular}{|c|c|c|c|c|c|c|c|c|c|}
\hline & & \multirow[b]{2}{*}{$\mathrm{N}$} & \multirow[b]{2}{*}{ Mean } & \multirow{2}{*}{\begin{tabular}{c|c|} 
Std. \\
Deviation
\end{tabular}} & \multicolumn{2}{|c|}{$95 \%$ Confidence Interval for Mean } & \multirow{2}{*}{\begin{tabular}{|l}
$F$ \\
value \\
\end{tabular}} & \multirow{2}{*}{$p$-value } & \multirow{2}{*}{\begin{tabular}{|l|}
$\begin{array}{l}\text { Eta } \\
\text { square }\end{array}$ \\
\end{tabular}} \\
\hline & & & & & Lower Bound & Upper Bound & & & \\
\hline \multirow[t]{4}{*}{ PPBs } & City & 501 & 17.1058 & 6.73667 & 16.5145 & 17.6971 & & & \\
\hline & Town & 467 & 17.8223 & 6.46918 & 17.2340 & 18.4105 & & & \\
\hline & Country & 1022 & 17.5039 & 6.18737 & 17.1241 & 17.8837 & & & \\
\hline & Total & 1990 & 17.4784 & 6.39753 & 17.1971 & 17.7596 & \begin{tabular}{|l|}
1.533 \\
\end{tabular} & .216 & 0.002 \\
\hline
\end{tabular}

As for hometown, the mean level of three groups are city $(\mathrm{N}=501$, Mean $=17.1058)$, town $(\mathrm{N}=467$, Mean $=$ $17.8223)$ and country $(\mathrm{N}=1022$, Mean $=17.5039)$, compared with the whole respondents $(\mathrm{N}=1990$, Mean $=$ 17.4784), it is not difficult to find that students from city are unlikely to participate in the lowest level of the three groups, although there is neither statistical significance among three groups nor effect of hometown on political participation, because of $F=1.533, p=.22>.05$, and eta squared $=0.002$ which is far away from 0.01 .

Students from city have more chance and channel to connect latest information and politician; however, they are negative in politics probably because understanding and connecting penetrating lead them to be lack of joy in participation. From the results, students from town in participation is higher than the other two-group students; conversely, the students from city is the lowest group, that economic gap between city and country gradually minimized, the rural students become focus on the participation which is the aggregation of right and obligation. When the rural students more positively participate, the urban students keep the speed, that also display a picture that the former is more active than the later students.

\subsubsection{Major}

A one-way between-groups analysis of variance was conducted to explore the impact of major on each political 
participation behavior. The 1990 participants are divided into four groups based on major, including G1 (Social Science $=510), G 2($ Science $=425), G 3($ Engineer $=530)$ and G4 $($ Medical $=525)$. According to the results of Table 5, there was a statistically significant difference on political participation at the $p<.05$ level, for three groups: $F(3,1990)=5.747, p=.001 * * *$ (two-tailed). Despite reaching statistical significance, the actual difference in mean scores between groups was small. The effect size, calculated using eta squared, was 0.01 . Post-hoc comparisons using the Tukey HSD test indicated that the mean score for Group1 $(\mathrm{M}=16.5647, \mathrm{SD}=$ 6.05206) was significantly different from both Group $2(\mathrm{M}=17.7106, \mathrm{SD}=6.20396)$ and Group $3(\mathrm{M}=18.1679$, $\mathrm{SD}=6.92848)$ without Group $4(\mathrm{M}=17.4819, \mathrm{SD}=6.23170)$; each Group 2 and 3 was only significantly different from both Group1, without all other groups; Group 4 did not differ significantly from all Group 1, 2 and 3 , that indicates medical major students was similar to the students from major social science, science and engineer.

Table 5. The results of One-way ANOVA between Major for political participation behaviors

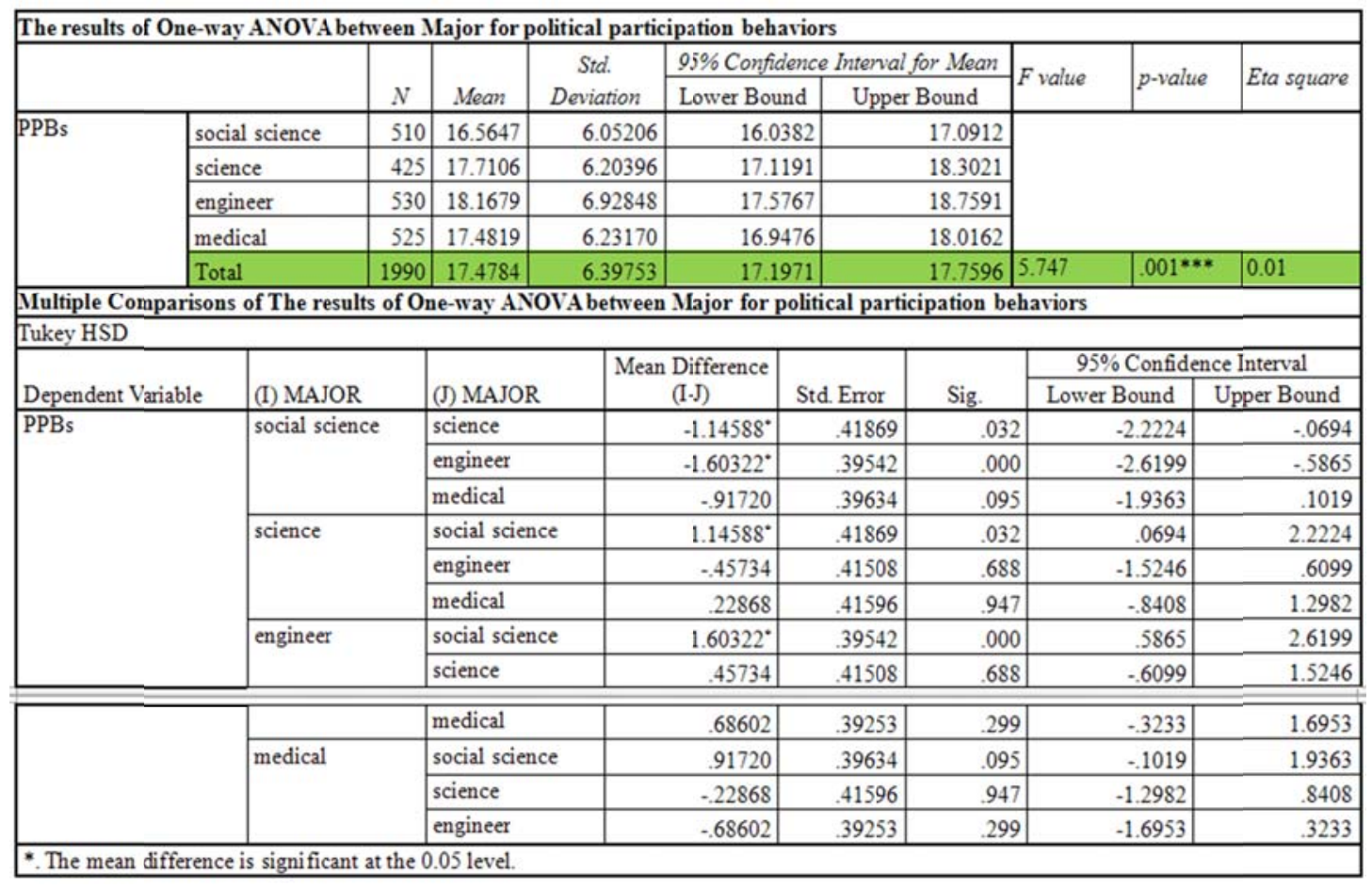

Compared with total using by mean score, social sciences students are in the lowest level; whereas engineer students are in the highest level among the four groups. And students from science and medical major are similar with the mean level. Variety of majors displays the effect on students' political participation, and the reasons presents as follows.

Different majors provide variety of knowledge and thinking aspects, even influence students' job choice; major influences both the level and ability of students' PP. Social science students should be more active and participate more activities than other majors' students (C. Gao, 2010); however, the reality of this research is opposite. Science and engineer students are salient compared with social science students that indicates major was not a hurdle to prevent or restrict students' participatory level, only if they would like to try or practice.

\subsubsection{Interest in Politics}

Many theorists of participation assume that citizens are autonomous and the best judges interests in politics. A one-way between-groups analysis of variance was conducted to explore the impact of Interest in politics on levels of each political participation behavior. The participants are divided into three groups, including $\mathrm{G} 1(\mathrm{~N}=$ 487), G2 ( $=846)$, and G3 $(\mathrm{N}=657)$.

According to Table 6, there was a statistically significant difference on PP at the $p=0.000 * * *<0.001$, for three groups: $F(2,1990)=23.079$; despite reaching statistical significance, the actual difference in mean scores between groups was small, the effect size, calculated using eta squared, was 0.023 . Post-hoc comparisons using the Tukey HSD test indicated that the mean score for Group $3(\mathrm{M}=18.7839, \mathrm{SD}=6.22903)$ was significant difference from both Group1 $(\mathrm{M}=16.3552, \mathrm{SD}=6.73293)$ and Group $2(\mathrm{M}=17.1111, \mathrm{SD}=6.16091)$; while, 
there was no significant difference between Group 1 and Group 2.

Table 6. The results of One-way ANOVA between Interests for Political Participation

\begin{tabular}{|c|c|c|c|c|c|c|c|c|c|c|}
\hline \multicolumn{11}{|c|}{ The results of One-way ANOVA between Interest for political participation } \\
\hline & & \multirow{2}{*}{$\mathrm{N}$} & \multirow{2}{*}{ Mean } & \multirow{2}{*}{ Std. Deviation } & \multicolumn{3}{|c|}{$95 \%$ Confidence Interval for Mean } & \multirow[t]{2}{*}{ Fvalue } & \multirow{2}{*}{$p$-value } & \multirow{2}{*}{ Eta square } \\
\hline \multirow{5}{*}{ PPBs } & & & & & & & & & & \\
\hline & No & 487 & 16.3552 & 6.73293 & & 15.7558 & 16.9547 & & & \\
\hline & Seldom & 846 & 17.1111 & 6.16091 & & 16.6954 & 17.5269 & & & \\
\hline & Some & 657 & 18.7839 & 6.22903 & & 18.3067 & 19.2611 & & & \\
\hline & Total & 1990 & 17.4784 & 6.39753 & & 17.1971 & 17.7596 & 23.079 & $.000^{* *}$ & 0.023 \\
\hline \multicolumn{11}{|c|}{ Multiple Comparisons for Interest in Politics } \\
\hline \multicolumn{11}{|l|}{ Tukey HSD } \\
\hline \multirow{8}{*}{\begin{tabular}{|l} 
Dependent Variable \\
PPBs
\end{tabular}} & \multirow{4}{*}{$\begin{array}{l}\text { (I) g3interest } \\
\text { No }\end{array}$} & \multirow{2}{*}{\multicolumn{2}{|c|}{ (J) g3interest }} & \multirow{2}{*}{\multicolumn{2}{|c|}{$\begin{array}{c}\text { Mean Difference } \\
\text { (I-J) }\end{array}$}} & \multirow{2}{*}{$\begin{array}{l}\text { Std. } \\
\text { Error }\end{array}$} & \multirow[b]{2}{*}{ Sig. } & \multicolumn{3}{|c|}{$95 \%$ Confidence Interval } \\
\hline & & & & & & & & Lower B & ound & Upper Bound \\
\hline & & \multicolumn{2}{|c|}{ Seldom } & \multicolumn{2}{|r|}{-75587} & .35992 & .090 & \multicolumn{2}{|c|}{-1.6001} & .0883 \\
\hline & & \multicolumn{2}{|l|}{ Some } & \multicolumn{2}{|c|}{$-2.42863^{\circ}$} & .37836 & .000 & \multicolumn{2}{|c|}{-3.3161} & -1.5412 \\
\hline & \multirow[t]{2}{*}{ Seldom } & \multicolumn{2}{|l|}{ No } & \multicolumn{2}{|r|}{.75587} & .35992 & .090 & \multicolumn{2}{|r|}{-.0883} & 1.6001 \\
\hline & & \multicolumn{2}{|l|}{ Some } & \multicolumn{2}{|c|}{$-1.67275^{\circ}$} & .32905 & .000 & \multicolumn{2}{|c|}{-2.4445} & -.9010 \\
\hline & \multirow[t]{2}{*}{ Some } & \multirow{2}{*}{\multicolumn{2}{|c|}{\begin{tabular}{|l|} 
No \\
Seldom
\end{tabular}}} & \multirow{2}{*}{\multicolumn{2}{|c|}{$\frac{2.42863^{\circ}}{1.67275^{\circ}}$}} & .37836 & .000 & \multicolumn{2}{|r|}{1.5412} & 3.3161 \\
\hline & & & & & & .32905 & .000 & & .9010 & 2.4445 \\
\hline
\end{tabular}

Political interest has small to moderate effect on levels of political participation, supporting by eta squared $=$ 0.023, that indicates interest is the best teacher. Compared with the total $(\mathrm{N}=1990$, Mean $=17.48)$, it is no hesitations that the more interest the students have the higher levels they participate. Different levels of political interest have stimulated respondents' enthusiasm in activities, and further to increase the level of political participation.

Albert Einstein stated "Interest is the best teacher" that guide people to do which they want to do (Fowler \& Kam, 2007; Kam, 2012). Political interest leads students to participate into politics: the more interest they have, the more positive in the behaviors. In the reality of this research, most of the results are the same like the former study conclusion, interest drives participatory behaviors (W. L. Bennett, Wells, \& Rank, 2009; Kim, 2013; Pattie et al., 2003; Scherman, Arriagada, \& Valenzuela, 2015).

Otherwise, it is no hesitate that more or less interest correlates to PPB, which probably students as accepting higher knowledgeable and law abiding group are easily to judge the right or wrong activities to participate or not. The more interest students have, the higher level participate they in; hence, university as the educational subject and family likes the growth backbone should put more attention on fostering students' interest in politics. In a nutshell, the more interest the students have the higher level they participate.

\subsubsection{Family Income per Year}

A one-way between-groups analysis of variance was conducted to explore the impact of Family income per year on levels of each political participation behavior. The participants are divided into 3 groups, including $\mathrm{G} 1(\mathrm{~N}=$ 778), G2 $(\mathrm{N}=764)$, and $\mathrm{G} 3(\mathrm{~N}=445)$. As Table 7 indicates, there was no statistic significant difference between three-groups of family income per year, because of the $p$ value is higher than 0.05 and eta square is less than 0.01 on political participation.

Table 7. The results of One-way ANOVA between Family Income for Political Participation

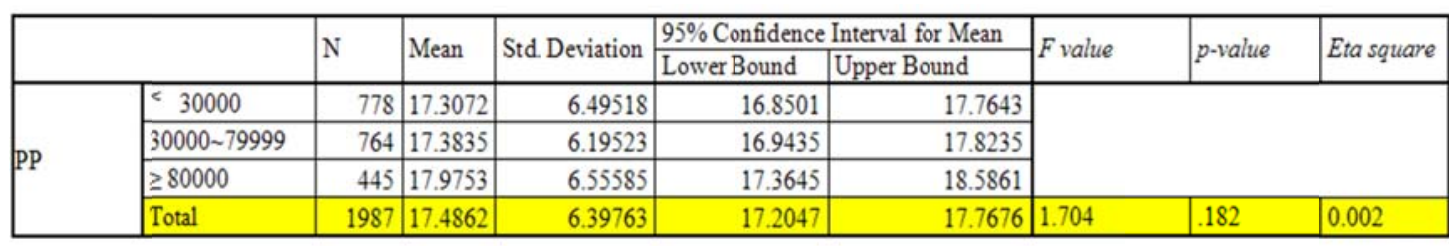

No matter students from poor, poverty or common income family, there is no statistical difference among the three family income groups with $F=1.704, p=0.182$, eta squared $=0.002$ that indicates family income cannot restrict the students' participatory degree. Only the mean participatory level of students from common family (N $=445$, Mean $=17.9753)$ is higher than the mean level of total $(\mathrm{N}=1987$, Mean =17.4862). The mean level of students' from poor and poverty family are similar, less than the average level.

Family income as an important resource in political participation, the better income they have, the higher level of participation they take (Brady et al., 1995; Showalter, 2001; Z. Wang \& Dai, 2013; Williams, 2008). According 
to Verba et al. (1995) SES model, the family-income as one of important influential factor, which had positive relation to political participation; however, in fact, the economic element cannot influence the level of PP. This reality indicates the participatory level of students is not related to family income that opposite to the previous study, probably because the students accepting the higher education acknowledge the obligation and responsibility of the political participation on the basis of understanding the political, economic and social status that lead them to participate equally.

Only considering the mean level of political participation by family income in this research, it is easy to find that the students from poverty family in campaign activities are higher than from poor family and lower than the normal income family, although there is no statistical difference between the three groups that indicates although the income of family is seldom, the students still seek the chance to participate in politics in order the right ideology.

In conclusion, the students have difference in the mean of the behavior; otherwise, the students in public university from poor, poverty or normal income family have no statistical difference and effects on political participation in this study.

\subsubsection{Political Knowledge-Store}

A one-way between-groups analysis of variance was conducted to explore the impact of political knowledge-store on levels of each political participation behavior. Based on the descriptive statistics, the respondents were divided into 3 groups based on knowledge-store, including the Group 1(Low knowledge group) is 0 and 1 right, and the Group 2 (Middle group) is 2 right answers group, and the Group 3 (High) is three and four right group.

Table 8. The results of One-way ANOVA between Political knowledge store for PP

\begin{tabular}{|c|c|c|c|c|c|c|c|c|c|c|}
\hline \multicolumn{11}{|c|}{ The results of One-way ANOVA between Political knowledge for political participation } \\
\hline & & \multirow{2}{*}{$\mathrm{N}$} & \multirow{2}{*}{ Mean } & \multirow{2}{*}{\begin{tabular}{|l} 
Std. \\
Deviation
\end{tabular}} & \multirow{2}{*}{\multicolumn{3}{|c|}{ 95\% Confidence Interval for Mean }} & \multirow{2}{*}{ Fvalue } & \multirow{2}{*}{$p$-value } & \multirow{2}{*}{ Eta square } \\
\hline & & & & & & & & & & \\
\hline \multirow{4}{*}{ PP } & Low & 849 & 18.3004 & 6.63879 & 17.8532 & \multicolumn{2}{|r|}{18.7476} & & & \\
\hline & Middle & 443 & 17.5282 & 6.45002 & 16.9259 & \multicolumn{2}{|r|}{18.1305} & & & \\
\hline & High & 698 & 16.4470 & 5.90777 & 16.0080 & \multicolumn{2}{|r|}{16.8860} & & & \\
\hline & Total & 1990 & 17.4784 & 6.39753 & 17.1971 & & 17.7596 & 16.340 & $.000^{* * * *}$ & 0.016 \\
\hline \multicolumn{11}{|c|}{ Table 5.8.2: Multiple Comparisons for Knowledge-Store } \\
\hline \multicolumn{11}{|l|}{ Tukey HSD } \\
\hline \multirow{2}{*}{ Dependent Variable } & \multirow{2}{*}{\multicolumn{2}{|c|}{$\begin{array}{l}\text { (I) group } 3 \text { political } \\
\text { knowledge }\end{array}$}} & \multirow{2}{*}{\multicolumn{2}{|c|}{$\begin{array}{l}\text { (J) group } 3 \text { political } \\
\text { knowledge }\end{array}$}} & \multirow{2}{*}{$\begin{array}{l}\text { Mean Difference } \\
(I-J)\end{array}$} & \multirow{2}{*}{ Std. Error } & \multirow{2}{*}{ Sig. } & \multicolumn{3}{|c|}{$95 \%$ Confidence Interval } \\
\hline & & & & & & & & Lower. & ound & Upper Bound \\
\hline \multirow{6}{*}{ PP } & \multirow{2}{*}{\multicolumn{2}{|c|}{ Low }} & Middle & & .77214 & .37210 & .095 & & -1006 & 1.6449 \\
\hline & & & High & & $1.85336^{*}$ & .32438 & .000 & & 1.0925 & 2.6142 \\
\hline & \multirow{2}{*}{\multicolumn{2}{|c|}{ Middle }} & Low & &. .77214 & .37210 & .095 & & -1.6449 & .1006 \\
\hline & & & High & & $1.08123^{*}$ & .38566 & .014 & & .1767 & 1.9858 \\
\hline & \multirow{2}{*}{\multicolumn{2}{|c|}{ High }} & Low & & $-1.85336^{*}$ & .32438 & .000 & & -2.6142 & -1.0925 \\
\hline & & & Middle & & $-1.08123^{*}$ & .38566 & .014 & & -1.9858 & -.1767 \\
\hline
\end{tabular}

Political knowledge-store have small to moderate effect on levels of political participation with eta squared $=$ 0.02. The mean level of total 1990 respondents is 17.4784, and Low knowledge $(\mathrm{N}=849$, Mean $=18.3004)$, Middle knowledge $(\mathrm{N}=443$, Mean $=17.5282)$ and the High knowledge $(\mathrm{N}=698$, Mean $=16.4470)$. Students with less knowledge-store have higher level of political participation that indicates practice can also bring knowledge. Students without knowledge are not fearing to practice anything, including participating into political activities.

In general, the level of knowledge-store has significant difference on most levels of political participation. Knowledge-store as an important index in political participation, and can measure the knowledge level in politics. The adequate knowledge can promote and increase the level of the participation (Bell \& Lewis, 2015; W. A. Galston, 2001; Kittilson \& Schwindt-Bayer, 2013; Mondak \& Halperin, 2008), and in this research has a difference findings.

In detail, there is a peculiar phenomenon in this research, only taking the mean level of all the political participation behaviors into account, the lower knowledge the students have, the higher participatory level in mean they stand. It is a paradox reality displays by the students in public university of Hebei province China, the knowledge-store did not increase the participation in politics; conversely, the less knowledge the students have, the higher level of participation they take, that can directly consider as "They that know nothing fear nothing", 
students with less knowledge-store reserve are more curious about political participation, and try their best as well as they can.

\section{Discussion}

The students' performance in politics concurs with some previous studies were low (Donát, 1991; Henn \& Foard, 2012; Kalaycioglu \& Turan, 1981; Vráblíková, 2010) tested by the frequency of eight behaviors. There are a number of reasons why participation may appear this result.

One obvious reason is that definition different. In this research, political participation is as a whole behavior which was measured by eight political activities related to the way individual chooses to influence government or press on government. It is wider than some scholars who emphasized political participation is just election (Milbrath, 1981; Scaff, 1975; van Deth, 2001), if only emphasized on voting behavior in the definition of PP, students' level of PP stands in moderate level based on Table 1, because the in this research, focus on the common behaviors which plays important role in respondents growth process and often occurs in daily life. Therefore, research scope of the range is one of the reasons why students are at low level.

The second reason is because that political activism is the process of collective outcome, and the personnel influence is relative low. Political acts can influence governmental leaders by exerting pressure or communicating information about preference (Ohme et al., 2017; Scaff, 1975; van Deth, 2001); however, single individual' influence is limited that's why political contact level in this research also keep in the low level, channel and methods restricts students' influential power. On basis of Table 1, students are unlikely to achieve political participation by political contact because individual neither contacts civil servant nor elected candidates seldom. Although the Constitution of PRC alleges that citizen have freedom of association, while the result cannot be judged legal or illegal and the influence of individual is small; therefore, students would rather be in low participatory level without loss, but also than participate in impact of bad future.

The third reason why students' political activism stays in low level is because of professional development. Participants in this study are the students whose first task is to master academic skill prepared for future development. In case immersing into participation, decreasing expense on study become a new trend and being busy in participating, compared with the benefit and cost, in order to have a better future, reducing participation is likely to be a no task choice.

Examining the effect of demographic information is aim to deeply on students' low level political participation. The effect from high to low of demographics is: gender, interest, political knowledge-store and major; whereas hometown and family income have no effect on political participation based on Table 9. Physiological factor (gender) plays the most important role in influencing the level of political participation; family background has no effect on political participation that violates the assumption of Verba's SES model. Knowledge-store displays negative influence to participation: the less knowledge the students have, the higher level of participation they take.

Table 9. The effect size of demographic information on political participation

\begin{tabular}{ccc}
\hline Variable & Eta squared & Effect size \\
\hline Gender & 0.041 & \\
Interest in politics & 0.023 & Small to moderate \\
Political knowledge-store & $0.016(0.02)$ & Small \\
Major & 0.01 & No \\
Hometown & 0.002 & \\
Family income per year & 0.002 & . \\
\hline
\end{tabular}

To propose and evaluate students' political participation behaviors in Hebei public universities was the first objective of this research. In order to achieve this objective, this research examined eight participatory behaviors. As the core in democratic politics and ruler to measure degree of political democracy, political participation has been concerned by the government and public. Participatory democracy requires citizen to have public spirit, care for public affairs and follow public rational choice. Students accepting higher education as the citizens are more prudent because knowledge strengthens mind and thinking. Knowledge makes the students full of energy to political activity and master the belief of "Thinking before leap" that is a good way for the participants in the process to make choice whether to do or not to do. Students are more initiative; transforming knowledge to practice is the motivation for students, furthermore, not considering the results to test knowledge right or wrong 
is the impetus in the process of participation.

Although "expanding citizens' political participation step by step" is in the report of 16th, 17th and 18th NCCPC, the students' low level political participation has already appeared in the result. Attributed to the following reasons:

First, the weak economic foundation restricts the range of participation. The material determines the consciousness; the economic basis determines the superstructure. Hebei province is an agricultural province, which provides food crops, vegetables, and labor force to Beijing and Tianjin, and surround the two cities, the per capita GDP in 2017 was 40,367 RMB ranking 19th among 34 provincial administrative regions nationwide (X. Xu, 2017), and is considered as the most underdeveloped in the provinces along eastern coast of China. Compared with developed province, the backward economy of Hebei province becomes the hurdle for political participation. "High-level political participation is always accompanied by higher levels of development, and social and economically more developed societies also tend to give higher value to political participation" (Huntington, 1998); therefore, increasing economic level, strengthening economic construction, creating an energetic economic environment are suitable methods to overcome the restriction of political participation.

Secondly, the backwardness of the cultural environment hinders the high-quality conducting political participation. After the foundation of the PRC, the education industry was vigorously developed and obtained some achievement; however, the educational level of Hebei province is lower than average level of provinces in China. There is no university which indicates the higher educational level in Hebei province in "Project 985 or 211", even the replacement "Double First Class University Plan"; neither the top university nor first class disciplines are the sorrow of education in Hebei province. Educational level is directly proportional to participatory level (Almond \& Verba, 1989), lagging high education in Hebei province produce the trouble in the process of political participation.

Thirdly, political system in Hebei province, even in China is unsound, and need to improve and develop. In general, system construction is unbalance to real practice. Facing emergency, the public mass need to deal promptly, and the government should handle immediately; however, the system does not give the answer how to deal or resolve. In the process of political activity, without policy-making chance, individual based on their willing decides to participate, maybe influence the result. Imperfect political system becomes the obstacle of low political participation.

Fourthly, traditional culture influence individual's behaviors. Politics is the politician's or political elite's politics, conventional representative democracy provides the concept which leads individual lost the interest because whether participate or not, the results were not influenced or changed by their activities.

In detail from the descriptive statistics of this study, undergraduates in public universities of Hebei province in China demonstrated a low level performance in politics. The standard political participation behavior vote is at a moderate to high level that indicates the students prefer to vote because the Constitution of ROC claims vote is the right and duty for each legal citizen of ROC. Every citizens should have equality in political activity not only during elections (Pateman, 1970, 1971). Students with high knowledge are familiar with the requirements of law, and shunning doing the activities which violate the law is the basic knowledge. The other relative participatory activities as the affinity behavior serving to vote were in lower level. The effects of personality traits as the internal elements are statistically and substantively significant regarding political participation. Similar as the previous study (W. K. T. Cho et al., 2006; Salisbury, 1975; Schlozman et al., 1999; Verba, Schlozman, Brady, \& Nie, 1993b), male and female students has statistical difference on the level of political participation as soon as gender has small to moderate effect on it. Individuals who have high interest in politics are more likely to participate, while those who have more political knowledge are less likely to participate into politics. Therefore, male students with more interest and less knowledge prefer to take part in low-level political activities.

Otherwise, there is no effect of family income and hometown on low level political participation, it different from the empirically research (Feldman, 1988; Karp \& Banducci, 2008; Kern, Marien, \& Hooghe, 2015), the family elements gradually lost its influence on political participation for Hebei public universities' students. The People's Republic of China is a world populous country, the government focuses on people, in order to protect and improve the people's livelihood and advance fairness and justice; since the17th NCCPC, government increased the public resource into education including increasing the educational facilitates, student loans and insurance, which provides more chances for students to contact the frontier information and political activities. Therefore, students obtain the benefits more from government instead of family. Government policy leads them to extend horizons and gain the equality chances of education without caring how much parents' income per year and where they come from, even if the family is poverty, the student loan can help to complete the study. Besides 
that it is not means the family factors is unimportant for students' growth, probably influencing students' psychology or other aspects is not referred in this research. It just implies family income cannot prevent students to participate into politics.

Based on the findings, the present study demonstrate that regional differences do not have an influence on students in the perspective of political volunteers, in this regard, outcome revealed that urbanization level also swell with respectively. One of the results in narrowing the gap between rural and urban areas and improving living conditions in rural is space integration, no matter where people live, the advanced communication technology promotes to share information at the same time through traditional devices like TV, broadcast, newspaper, or modern network equipment, especially after the requirement of "Internet Plus" policy 2015 by primer Li Keqiang. Technology reformation decreases the distance from rural and urban students who can get the same information and enjoy the social innovation as soon as possible. When the space integrated, hometown in rural or urban is not important, put how much attention into politics are more decided by the students' internal causes, for example, interest in politics, gender and political knowledge which are discussed before.

On the basis of the results, major as one of key elements separated students in university has small effect on political participation; however, different from the traditional result (Jin \& Zhang, 2008; W. Gao, 2009), social science students stand into the lowest-level political participation. Following the "educational extending policy", students have more and more chance to accept higher education as well as choose the major which like best judging by the remarks of College Entrance Examination. Major selected is similar to participatory enthusiasm, internal willing is critical for the result, to participate or not. The major of Engineer was concentrated the students with quick-wittedness and operating capability, those students are more likely to focus on the new, positively try and bravely accept failure; to some extent, political participation is new, and they do not know the result is success or failure at beginning, however, they take part in the process in order to achieve the goal. Some proponents claim "politics is social science", social science students should be more expert in this part, conversely, the result in this research indicates those students in social science are in lowest level in the four major groups. Social science students with subtle consider the results more, after calculating the benefit and cost and then deciding to do or not to do.

In summary, these lower levels of political participation among Hebei province public universities students are blamed on the personal factors (internal factors) and major-selected. Due to the different definition of political participation, law personnel influence and professional development, the students' performance in politics concurs with some previous studies in this study were low tested by the frequency of eight behaviors. Moreover, there were four reasons that led to the low political participation behaviors in public universities of Hebei Province, which were the weak economic foundation, the backwardness of the cultural environment, the unsound political system and the influence of traditional culture. In addition, as Hebei province plays a significant role to implement Jing-Jin-Ji integrated policies which carried out on 2013, political participation among Hebei province public universities students need to improve and develop.

\section{References}

Almond, G. A., \& Verba, S. (1989). The civic culture: Political attitudes and democracy in five nations (1st ed.). Princeton: Princeton University Press.

Bell, S., \& Lewis, J. (2015). A survey of civic engagement education in introductory Canadian politics courses. The Canadian Journal for the Scholarship of Teaching and Learning, 6(1), 1-19. https://doi.org/10.5206/cjsotl-rcacea.2015.1.2

Bennett, W. L., Wells, C., \& Rank, A. (2009). Young citizens and civic learning: Two paradigms of citizenship in the digital age. Citizenship Studies, 13(2), 105-120. https://doi.org/10.1080/13621020902731116

Brady, H. E., Verba, S., \& Schlozman, K. L. (1995). Beyond Ses: A resource model of political participation. The American Political Science Review, 89(2), 271-294. https://doi.org/10.2307/2082425

Cho, W. K. T., Gimpel, J. G., \& Wu, T. (2006). Clarifying the role of SES in political participation: Policy threat and Arab American mobilization. The Journal of Politics, 68(4), 977-991. https://doi.org/10.1111/j.1468-2508.2006.00482.x

Cohen, J. (1988). Statiscal power analysis for the behavioral sciences (2nd ed.). Lawence Erlbaum Associates.

Donát, P. (1991). Measuring behaviour: The tools and the strategies. Neuroscience and Biobehavioral Reviews, 15(4), 447-454. https://doi.org/10.1016/S0149-7634(05)80130-7

Feldman, S. (1988). Structure and consistency in public opinion: The role of core belifs and values. American 
Journal of Political Science, 32(2), 416-440. https://doi.org/10.2307/2111130

Fowler, J. H., \& Kam, C. D. (2007). Beyond the self: Social identity, altruism, and political participation. Journal of Politics, 69(3), 813-827. https://doi.org/10.1111/j.1468-2508.2007.00577.x

Galston, W. A. (2001). Political knowledge, political engagement, and civic education. Annual Review of Political Science, 4(1), 217-234. https://doi.org/10.1146/annurev.polisci.4.1.217

Gao, C. (2010). An investigation of contemporary college students' political participation-- A case study in some universities of Wuhan. Wuhan University of Technology (Social Science Edition), 23(2), 282-285.

Gao, W. (2009). Factor analysis on undergraduates' political participation in China. Journal of China Youth College for Political Sciences, (2), 23-29.

Henn, M., \& Foard, N. (2012). Young people, political participation and trust in Britain. Parliamentary Affairs, 65(1), 47-67. https://doi.org/10.1093/pa/gsr046

Huntington, S. P. (1998). The clash of civilization and the reconstruction of the world order. Xinhua Publishing House.

Jiang, Y., \& Liu, J. (2013). The analysis of college students' political participation influencing factors. Journal of Chongqing University (Social Science Edition), 19(4), 166-171.

Kam, C. D. (2012). Risk attitudes and politial participation. American Journal of Political Science, 56(4), 817836. https://doi.org/10.1111/j.1540-5907.2012.00605.x

Kalaycioglu, E., \& Turan, I. (1981). Measuring political participation: A cross-cultural application. Comparative Political Studies, 14(1), 123-125. https://doi.org/10.1177/001041408101400106

Karp, J. A., \& Banducci, S. A. (2008). Political efficacy and participation in twenty-seven democracies: How electoral systems shape political behaviour. British Journal of Political Science, 38(2), 311-334. https://doi.org/10.1017/S0007123408000161

Kern, A., Marien, S., \& Hooghe, M. (2015). Economic crisis and levels of political participation in Europe (2002-2010): The role of resources and grievances. West European Politics, 38(3), 465-90. https://doi.org/10.1080/01402382.2014.993152

Kim, S. (2013). Relational model of political participation: Tackling "identity-to politics link" through latent class models. In 9th Annual Center for the Study of Democracy California Graduate Student Conference "Diverse democracies: Ideas, institutions, populations." Irvine.

Kittilson, M. C., \& Schwindt-Bayer, L. A. (2013). The gendered effects of electoral institutions: Political engagement and participation. Oxford: Oxford University Press.

Lin, S. (2011). People, party and state: The politic analysis of the development of people's democracy. Fudan Journal (Social Sciences), 5, 1-10.

Milbrath, L. W. (1981). Political Participation. In S. L. Long (Ed.). The handbook of political behavior (pp. 197240). Boston: Springer.

Mondak, J. J., \& Halperin, K. D. (2008). A framework for the study of personality and political behavior. British Journal of Political Science, 38(2), 335-362. https://doi.org/10.1017/S0007123408000173

Ohme, J., de Vreese, C. H., \& Albæk, E. (2017). From theory to practice: How to apply van Deth's conceptual map in empirical political participation research. Acta Politica, 1-24. https://doi.org/10.1057/s41269-017-0056-y

Pateman, C. (1970). Participation and democratic theory. Cambridge University Press (1st ed.). London; New york; Melbourne: Cambridge University Press.

Pateman, C. (1971). Political culture, political structure and political change. British Journal of Political Science, 1(3), 291-305. https://doi.org/10.1017/S0007123400009133

Pattie, C., Seyd, P., \& Whiteley, P. (2003). Citizenship and Civic Engagement: Attitudes and Behaviour in Britain. Political Studies, 51(3), 443-468. https://doi.org/10.1111/1467-9248.00435

Salisbury, R. H. (1975). Research on political participation. American Journal of Political Science, 19(2), 323341. https://doi.org/10.2307/2110440

Scaff, L. A. (1975). Two concepts of political participation. The Western Political Quarterly, 28(3), 447-462. https://doi.org/10.1177/106591297502800303 
Scherman, A., Arriagada, A., \& Valenzuela, S. (2015). Student and environmental protests in Chile: The role of social media. Politics, 35(2), 151-171. https://doi.org/10.1111/1467-9256.12072

Schlozman, K. L., Verba, S., \& Brady, H. E. (1999). Civic participation and the equality problem. In T. Skocpol \& M. P. Frorina (Eds.), Civic engagement in American democracy (1st ed., p. 531). Washington D.C.: BROOKINGS INSTITUTION PRESS.

Showalter, P. H. (2001). Assessing the level and the nature of political participation among academic librarians in North Carolina. Chapel Hill: the University of North Carolina.

Williams, M. (2008). The roots of participatory democracy: Democratic communists in South Africa and Kerala, India. Palgrave Macmillan (1st ed.). New York: Palgrave Macmillan.

van Deth, J. W. (2014). A conceptual map of political participation. Acta Politica, 49(3), 349-367. https://doi.org/10.1057/ap.2014.6

Verba, S., \& Nie, N. H. (1972). Participation in America: Political democracy and social equality (1st ed.). New York: Haper \& Row.

Verba, S., Schlozman, K. L., Brady, H. E., \& Nie, N. (1995). American citizen participation study, 1990. Chicago: University of Chicago; National Opinion Research Center.

Verba, S., Schlozman, K. L., Brady, H. E., \& Nie, N. H. (1993). Race,ethnicity and political resources: Participation in the United States. British Journal of Political Science, 23(4), 453-497. https://doi.org/10.1017/S0007123400006694

Vráblíková, K. (2010). Contextual determinants of political participation in democratic countries. In Conference Research on Nationalism, Ethnicity and Multiculturalism (CRONEM) (pp. 1-26). Guildford.

Wang, Z., \& Dai, W. (2013). Women's participation in rural China's self-governance: institutional, socioeconomic, and cultural Factors in a Jiangsu County. Governance, 26(1), 91-118. https://doi.org/10.1111/j.1468-0491.2012.01605.x

Xu, X. (2017). Research on the influencing factors of college teachers' engagement. Teaching Staff Development, (5), 74-75.

Zhao, Z., \& Tang, X. (2008a). Undergraduates' political participation--analysis of five Nanjing universities. Educational Research and Experiment, (6), 37-41.

Zhou, S. (2014). Development oriented participatory democracy: A path analysis of Chinese democratic construction. Journal of Political Science, 17(2), 59-67.

\section{Copyrights}

Copyright for this article is retained by the author(s), with first publication rights granted to the journal.

This is an open-access article distributed under the terms and conditions of the Creative Commons Attribution license (http://creativecommons.org/licenses/by/4.0/). 